\title{
Mission for Vision: Assessing \& Supporting Youngsters with Visual Impairment
}

\author{
Tammy Haight, LPN \\ Carol M. Shepherd, ED.D \\ Full Professor \\ National University \\ 11255 N. Torrey Pines Road \\ San Diego, CA 92037 \\ USA
}

\begin{abstract}
Diagnosis of visual problems among youngsters is in great part incumbent upon teachers and school nurses, who spend considerably more time with school-aged children than their parents or guardians. Symptoms of visual challenges in students are not always obvious. It is vital that these teachers and nurses receive appropriate instruction to recognize the signs of visual impairment in youngsters and be able to assess and support these children so they may develop skills to effectively adapt to everyday living and their environment.
\end{abstract}

Keywords: visual impairment in school children, visual disability, echolocation

\section{Introduction}

Imagine waking up and not being able to see the numbers on the alarm clock on the bedside. Not only the clock, but everything in the room would also be a blur. Feelings of anxiety and fear would immediately set in. Now, what if an eye exam or corrective lenses could not remedy the issue? Then what? Vision is an essential part of everyday life, influencing how Americans of all ages learn, communicate, work, play, and interact with the world (Vision, 2017). Infants rely on their limited sight and eventually their eyes mature to focus on the surroundings. How will the parents know for sure that their child can see? Are there signs other than the movements of their heads? Visual impairment refers to a loss of visual acuity, where the eye does not see objects clearly. A loss of visual field means the eye cannot see as wide an area as usual without moving the eyes or turning the head (Kids', 2015). This condition can be difficult to assess. First, young children are frequently victims because vision issues are often overlooked or undiagnosed. Second, lack of follow up care after failed vision screening in schools continues to be an issue, as well as accuracy in detecting the signs and symptoms. Lastly, vision impairment brings on feelings of insecurity in the individual. This leads to stress, often resulting in behavioral and psychological issues. Millions of children live with visual impairment, and many more remain at risk for eye disease and preventable eye injury. Early detection, timely treatment and use of vision rehabilitation services are not always available or accessible (Vision, 2017).

\section{The Problem}

Visual impairment and low vision in school-aged children are often overlooked. Failure to recognize the need for corrective glasses remains the primary factor responsible for vision problems and concerns. Those who struggle with poor vision are unaware of the problem because this is the way they have always seen things, and they do not have a comparison. Visually impaired children use several kinds of sensory information to navigate and understand the world around them. Hearing is a sense that helps them to compensate for their inability to see. This echolocation, defining their space by the bouncing of sound waves, helps them to monitor their environment. Many such youngsters are naturally sensitive to reflected sounds. Teachers and school nurses, along with specialists, can provide students with techniques to get the greatest amount of sensory information to enable them to understand the space around them (Baguhn \& Anderson, 2018).

Initially, children with visual impairments are often withdrawn and avoid participation in school and sports. They may appear socially isolated, with fewer friends and smaller social networks than fully sighted children may. These symptoms are frequently overlooked due to similarities in child behaviors and the connection to other disorders. Rarely is vision linked to childhood behaviors, making vision impairment difficult to detect (Huurre, 1999). A study conducted on behalf of the Association of Optometrists found that the majority of parents do not realize the impact that visual problems can have on the long-term health of their children. 
For example, the study shows that $83 \%$ of parents are unaware that these problems can lead to developmental delays, and $57 \%$ are unaware that these problems may be the cause of behavioral issues and lack of attention span. According to Dr. Amanda Farley, President of BC Doctors of Optometry, "We know that $80 \%$ of a child's learning is achieved through what they can see, so identifying vision problems early is vital for a young child to grow into their full potential" (2017). The study also found that parents ranked eye health among one of the lowest priorities for the child's overall health, with only $22 \%$ choosing it as one of their top three concerns. The statistics are particularly disconcerting because many common problems with vision can mimic symptoms of other childhood development issues, including Attention Deficit Hyperactivity Disorder (ADHD), dyslexia, and speech impediments $(B C, 2017)$. In 2017, according to the American Optometric Association, one in five preschoolers has vision problems, and $25 \%$ will need or wear corrective lenses by the time they enter school (Evidence-based, 2017). However, according to the 2015 disability statistics report provided by Cornell University, in the United States, $0.78 \%$ of non-institutionalized individuals reported a visual disability (Erickson, Lee, \& von Schrader, 2017). This is further evidence that visual impairment is difficult to diagnose, and that even those who suffer from this disability are not aware of their condition.

\section{Assessment and Support}

Detection of visual impairment via screening is an important function of the school nurses' role to promote optimal academic outcomes in school-aged children. Parental cooperation is an essential component for the follow up care and subsequent treatment. This remains a problematic issue as research reveals inconsistent follow up and a low rate adherence to school nurse screening referral recommendations (Kimel, 2006). There is a need to explore additional approaches to improve parental attention and adherence to treatment after a failed vision screening among school-aged children. In another school vision study, the first visit to an eye care specialist took an average of 18 months after initial failed vision screening by a school nurse. The reason for the delay was a lack of symptoms expressed by the child and a lack of recognition by the teacher and parents. Low income and cultural reasons are also barriers to seeking eye care for children, especially among Hispanic immigrant parents. In their culture, it is not customary to obtain eye care. Lowincome familieswhose children attend large elementary schools often lack health insurance due to low finances. Financial problems were reported by $31 \%$ of parents, although $78 \%$ reported having either Medicaid or private insurance with vision coverage, and about $20 \%$ had insurance without vision coverage. Interestingly, most would have qualified for programs providing free exams and glasses at low or no cost. Parents are unaware that the actual school nurse who provided the screening could have linked them to these services (Neville, 2015).

Lastly, vision impairment brings on feelings of insecurity, inability to deal with peer pressure, bullying, and psychological issues, which can lead to behavioral issues. As children transition into young adolescence, feelings of insecurity and peer pressure are common and may not be associated with disabilities such as vision impairment. Therefore, early detection of poor vision at a young age is imperative. According to a study in 2004, vision difficulties and school learning problems have been well documented. At least $20-25 \%$ of all children have vision problems (Hurre,1999). A study in Kentucky showed that vision problems among school-aged children indicated that $80 \%$ of children with reading disabilities have visual deficits. These children were also reported to act out and misbehave because they could not focus on academic tasks. The Snellen E chart to screen vision can identify only $5 \%$ of vision problems in youngsters. According to a children's vision awareness study, 28\% were taken to their family doctor rather than an ophthalmologist for further evaluation (Kimel, 2006). Communities, schools, and sports organizations must recognize subtle signs of visual impairment and recommend local resources, eye care referrals, screening and examinations. Timely treatment is vital. It is important that the use of vision rehabilitation services be recommended or brought to the attention of those in need of these services.

School nurses as well as teachers are concerned about the impact of health issues on students' ability to function effectively in the school setting. Interventions are designed to promote optimal well-being and learning, since $80 \%$ of what children learn is through vision. Studies show that good vision is critical to the learning process. Children with untreatable visual impairment often struggle with reading. Those affected by poor vision lose their place when reading, have difficulty copying, and tend to omit letters, misalign numbers and have problems with Scantron sheets. In addition to learning disabilities, physical discomfort and straining can lead to facial, neck and shoulder tension. Posture suffers a great deal due to hunching over and struggling to see, resulting in body aches and pains.Headaches occur, and are an obstacle to learning. These discomforts decrease the ability of students to focus and concentrate. Vision affects the safety of a child as well. Students can trip, fall, miss steps and lose their balance, causing bodily harm as well as ridicule from peers.

\section{Role of Teachers and School Nurses}

The role of teachers and school nurses in assessing and accommodating students with visual challenges is continually changing, especially with those students who exhibit less obvious evidence of impairment. 
Visual impairment affects the entire school day, and involves the students' daily routine, academics, communication, mobility, and much more (Ely \& Morse, 2018). School nurses are trained to screen and alert parents to possible vision problems in their children. Nurses can make a difference by providing awareness of actual eye diseases and the symptoms associated with these diseases. After determining that a student has a visual impairment, teachers and school nurses have three major roles: 1) provide necessary accommodations related to vision for the entire school day; 2) inform all personnel who will interact with student during the school day, and 3) provide specialized instruction and accommodative supports to meet the needs of the student (Ely \& Morse, 2018).

Nurses can recommend genetic counseling and connect parents with community resources. The routine screenings preformed in schools are not diagnostic and do not replace examinations by eye care professionals; therefore, parental involvement in following through with vision care is imperative (Neville, 2015). Screening without follow up care has little value. Most school nurses and teachers of youngsters with visual impairments are passionate about their desire to have students guided in their education, treated with respect, and enabled and encouraged to grow into independent, productive citizens. Such professionals spend a great deal of time, both during and after work hours, planning lessons that will stimulate these youngsters and enable them to enjoy learning (Pogrund, 2018). Nurses can help by introducing interesting, catchy and enjoyable ways to make children aware that they are not alone in their disability. Colorful, entertaining posters and handouts can help bring awareness of visual challenges to everyone. Diseases such as Stargardts, Bests, age-related macular degeneration, Macular Dystrophy and retinal disorders are among a few diseases that parents may never have heard of, but which exist. It is the nurses' role to facilitate and recommend follow up care and assist the parents and guardians in taking that first step toward early detection. Visual impairment professionals are facing an ever-changing, developing role. With research and progress in the field of visual impairment, more strategy options are becoming available for school nurses and teachers in an effort to meet the needs of students in their care, and to assist families in working with their visually challenged children (Ely \& Morse, 2018).

\section{Conclusions and Recommendations for Future Research}

Overall, as evidenced by studies and research, there is a vital need for awareness on the issue of eye care and health. Numerous state and local agencies exist to provide resources for visually challenged individuals and their families. As an example, there is The Center for Vision Loss, located in Stroudsburg, Pennsylvania. This site was selected because of the wide range of support they offer. The Center for Vision Loss believes that individuals challenged by severe vision loss should not have to choose between curtailing activities they once enjoyed and retaining their independence. This non-profit agency, a member of the Pennsylvania Association for the Blind, serves the residents of Lehigh, Northampton and Monroe Counties in Eastern Pennsylvania who are blind or visually impaired, enabling them to lead well-adjusted, rewarding and productive lives. This center works with all insurance providers, social security disability act programs, and Individual Education Planson a community health need that is of vital importance (www.CenterForVisionLoss.org).

May-West, Craig, and Wilder (2018) conducted a study on severely visually challenged individuals involved in a recreational activity. The purpose of this study was to begin investigating an underserved population within disability research: people with significant visual impairment. While several important findings resulted from the current study, any of these themes (being with others, freedom, equality), as well as the concept of hardiness, could apply to all school children. Findings suggest that individuals with significant visual impairment have unique needs and face unique struggles that are unlike those faced by other disability populations and, therefore, more research is needed to discover ways to help these youngsters adapt to recreational activities enjoyed by the general population of schoolchildren (May-West, Craig, \& Wilder, 2018). Only by knowledge and employment of such opportunities can visually challenged students be aided and given the opportunity to succeed in school and develop to their full potential. It is of vital importance that future school nurses and future teachers be educated in ways of effectively working with youngsters with disabilities who will be part of their caseloads and their classes. Institutions of higher education which prepare individuals to become educators must provide this type of instruction in their curricula. This paper focuses on the importance of future educators learning to assess, teach, and support youngsters who are visually impaired. Such children do not always exhibit obvious signs of their disability. To be effective, educators must be sensitized to the nature of these visual disabilities. Awareness of their needs and appropriate accommodations and support are necessary for the successful development of these youngsters into productive, confident adults. A search of the available literature is a strong indication that additional research is vitally needed in this area.

\section{References}

Baguhn, S., Anderson, D. (2018). Echoidentification: Teaching individuals with visual impairments to get the most back from sound. Journal of Visual Impairment \& Blindness (online), 112(5). Retrieved from ProQuest database. 
BC doctors of optometry highlights need for children's visionhealth. (2017). Health \& Beauty Close-Up. $<$ https://search-proquestlibprox.northampton.edu.libprox.northampton.edu/docview/1946993765?accountid=39096>.

Ely, M., \& Morse, M. (2018). Cerebral visual impairment: The conversation continues. Journal of Visual Impairment $\&$ Blindness (online), 112(5). Retrieved from ProQuest database.

Erickson, W., Lee, C., \& von Schrader, S. (2017).Disability statistics from the American Community Survey (ACS). Ithaca, NY: Cornell University Yang-Tan Institute (YTI). Retrieved from Cornell University Disability Statistics. Website: www.disabilitystatistics.org

Evidence-Based Clinical Practice Guideline Comprehensive Pediatric Eye and Vision Examination.(2017). American Optometric Association. Website: www.aoa.org

Huurre, T., Komulainen, E., \& Aro, H. (January, 1999).Social support and self-esteem amongadolescents with visual impairments. Journal of Visual Impairment \& Blindness, 93(1):26-37. Retrieved from http;//web. Ebsco Host. com.

Kids' Quest. (2015, February 07). Retrieved October 18, 2017, <https://www.cdc.gov/ncbddd /kids/vision.htm>.

Kimel, L. (2006). Lack of follow up exams after failed school vision screenings; An investigation of contributing factors. Journal of School Nursing, 22(3), 156-162, <http://eds.a.ebscohost.com /eds/pdfviewer?vid=5\&sid=5c46c267-5b51-49a9444aeec74e85c67percentage40sessionmgr4008>.

May-West, E., Craig, P., \& Wilder, A. (2018). The meaning of cross-country skiing for persons with significant visual impairment: A phenomenological study. Therapeutic Recreation Journal, 52(4), 349-373. Retrieved from ProQuest database.

Neville, K., Radii, E., \& Velmer, G.(2015). Improving parental adherence to a failed vision screening referral in the United States. British Journal of School Nursing,10(3),135-143,<http://eds.a.ebscohost.com/eds/detail/detail? vid $=13 \&$ sid $=884$ ef52a-e285 86c42b2a5712

Pogrund, R. (2018). Commitment and passion of professionals in the visual impairment field. Journal of Visual Impairment \& Blindness (online), 112(5). Retrieved from ProQuest database.

Vision. (2017, July), HealthyPeople2020, retrieved from, https://Healthypeople.gov/2020topics. 